\title{
Precise occlusion and trophic niche differentiation indicate specialized feeding in Early Devonian jawed vertebrates
}

\author{
Stephanie A. Blais ${ }^{a *}$ \\ ${ }^{a}$ Department of Biological Sciences and Laboratory for Vertebrate Palaeontology, University of Alberta, \\ Edmonton, AB T6G 2E9, Canada \\ *Stephanie.Blais@ualberta.ca
}

\begin{abstract}
Acanthodians may represent a paraphyletic assemblage of stem chondrichthyans, stem osteichthyans, stem gnathostomes, or some combination of the three. One of the difficulties in determining the phylogenetic affinities of this group of mostly small, spiny fishes is that several subgroups of acanthodians are represented by relatively little information in the fossil record. It is becoming increasingly apparent that to understand the evolution of gnathostomes, we must understand more about acanthodians. This study uses micro-computed tomography to test hypotheses about acanthodian jaw function, and in doing so provides insight into the form, function, and ecological role of ischnacanthiform acanthodian jaws and teeth from an extraordinary Early Devonian fossil locality in the Northwest Territories of Canada. The results of this study suggest that ischnacanthiform acanthodians may have coexisted by trophic niche differentiation, employing specialized feeding strategies during the Silurian and Early Devonian.
\end{abstract}

\section{OPEN ACCESS}

\section{Citation: Blais SA. 2017. Precise occlusion and trophic niche differentiation indicate specialized feeding in Early Devonian jawed vertebrates. FACETS 2: 513-530. doi: 10.1 I 39/facets-20 I 6-0030 \\ Editor: David C. Evans \\ Received: June 20, 2016}

Accepted: May 15, 2017

Published: June 20, 2017

Copyright: () 2017 Blais. This work is licensed under a Creative Commons Attribution 4.0 International License (CC BY 4.0), which permits unrestricted use, distribution, and reproduction in any medium, provided the original author(s) and source are credited.

Published by: Canadian Science Publishing
Key words: ischnacanthiform, acanthodian, Devonian, vertebrate jaws, bite mechanics, paleoecology

\section{Introduction}

Acanthodians were generally small, spiny fishes that are represented in the fossil record from the Early Silurian (Hanke et al. 2001b; Karatajute-Talimaa and Smith 2002; Burrow 2003) to the Permian (Denison 1979) by mostly disarticulated scales, fin spines, and teeth. Several phylogenetic analyses have suggested that acanthodians as a group most likely represent a paraphyletic assemblage of stem chondrichthyans (Brazeau 2009; Davis et al. 2012; Zhu et al. 2013; Giles et al. 2015; Long et al. 2015b; Burrow et al. 2016). It has become increasingly clear that understanding acanthodians is integral to our understanding of early gnathostome phylogenetic relationships, and that conditions in acanthodians may reflect the primitive conditions for at least some crown group gnathostomes.

Compounding the problem of acanthodian interrelationships is a relative dearth of fossil material and lack of comparable characters among acanthodians and between acanthodians and other gnathostome groups. Articulated acanthodian specimens are rare, particularly ischnacanthiform acanthodians (Valiukevičius 1992; Burrow 2004; Burrow and Rudkin 2014). The vast majority of ischnacanthiform acanthodian specimens are disarticulated dermal tooth-bearing elements referred to as dentigerous jaw bones (Long 1986; Hanke et al. 2001b; Burrow 2004, 2007; Hairapetian et al. 2006; Voichyshyn and Szaniawski 2012). These dentigerous jaw bones are often isolated and disarticulated, and often represent the only source of information upon which to base diagnosis and 
description of new species. Although the dentition is used to describe and differentiate new ischnacanthiform species, few studies have focussed on comparing dental characters among gnathostome groups, or attempting to use the dentition to provide insight into ischnacanthiform acanthodian ecology or biological role. As a result, we understand relatively little about how ischnacanthiform acanthodians interacted with each other or the other organisms inhabiting their environment.

Feeding mechanisms in extant fishes are often highly variable among species, and jaws and teeth provide valuable information about their ecological and biological roles (Darras 2012; Bellwood et al. 2014; Gibson 2015). Despite the relatively poor fossil record, paleontologists have made attempts to characterize jaw occlusion and feeding mechanics in ischnacanthiform acanthodians. The eminent paleohistologist Tor Ørvig, in his work on acanthodian dentitions (Ørvig 1973), described the jaw occlusion in ischnacanthiforms as interlocking, with the tooth cusps on one jaw bone coming into contact with the inter-tooth pit on the medial side of the opposing jaw bone. Ørvig (1973) suggested that this type of occlusion also explained the type of tooth wear exhibited in ischnacanthiforms, in which the posteriormost teeth were worn down to "stumps" by striking against this opposing intertooth pit.

Burrow (2004), in her review of acanthodians with dentigerous jaw bones, suggested that the jaws of Silurian-Early Devonian ischnacanthiforms occluded in a dorsoventral cog-like action, and agreed with Ørvig's (1973) interpretation of the tooth wear. According to these interpretations, the teeth were blunted by occluding with the inter-tooth pit of the opposing jaw bone. The older, posteriormost teeth were thus worn down from this contact, explaining why the posterior teeth of most ischnacanthiform acanthodians are short and blunt, as opposed to the longer, more fang-like teeth at the anterior end of the jaw bones. The jaws of Middle-Late Devonian forms, according to Burrow (2004), occluded in a more complex shearing action that sharpened, rather than blunted, the teeth. The later ischnacanthiforms were interpreted to employ more sophisticated feeding strategies than their Silurian-Early Devonian predecessors. These studies were based on observations of isolated dentigerous jaw bones, and the majority of these had been taphonomically distorted and flattened. In this study, I use wellpreserved fossils from the Northwest Territories of Canada to reconstruct ischnacanthiform acanthodian jaws to attempt to provide insight into their life position and occlusion.

Fossils from the Early Devonian Man On The Hill (MOTH) locality are extraordinarily wellpreserved. In addition to many agnathan taxa, acanthodians and stem chondrichthyans have been recovered (Bernacsek and Dineley 1977; Gagnier et al. 1999; Hanke et al. 2001a, 2001b; Hanke 2002; Hanke and Wilson 2004, 2006; Blais et al. 2011, 2015; Scott and Wilson 2012), including nearly complete articulated specimens of ischnacanthiform acanthodians (Fig. 1). Specimens of ischnacanthiform acanthodians from MOTH, when articulated, are commonly preserved with their mouths tightly closed and the lateral surfaces of their jaws either exposed or covered by superimposed scales. When the teeth are visible, they appear to occlude in a tightly interlocking fashion, with each tooth cusp medial to, and hidden from view by, the lateral anteroposterior flanges of the opposing teeth (Figs. 1B, 1C).

In addition to articulated specimens, disarticulated ischnacanthiform jaws are also relatively abundant at the MOTH locality (Fig. 2). Some of these are preserved with their associated mineralized cartilages, allowing them to be readily identifiable as upper or lower jaws. In addition, several specimens have been recovered comprising articulated pairs of upper and lower jaws, with their associated cartilages.

These articulated jaws offer an opportunity to accurately reconstruct the occlusion of the jaws and teeth and to indirectly test hypotheses about the possible ecology of these animals. Based on the relationship between species coexistence and trophic niche partitioning in analogous extant and extinct 

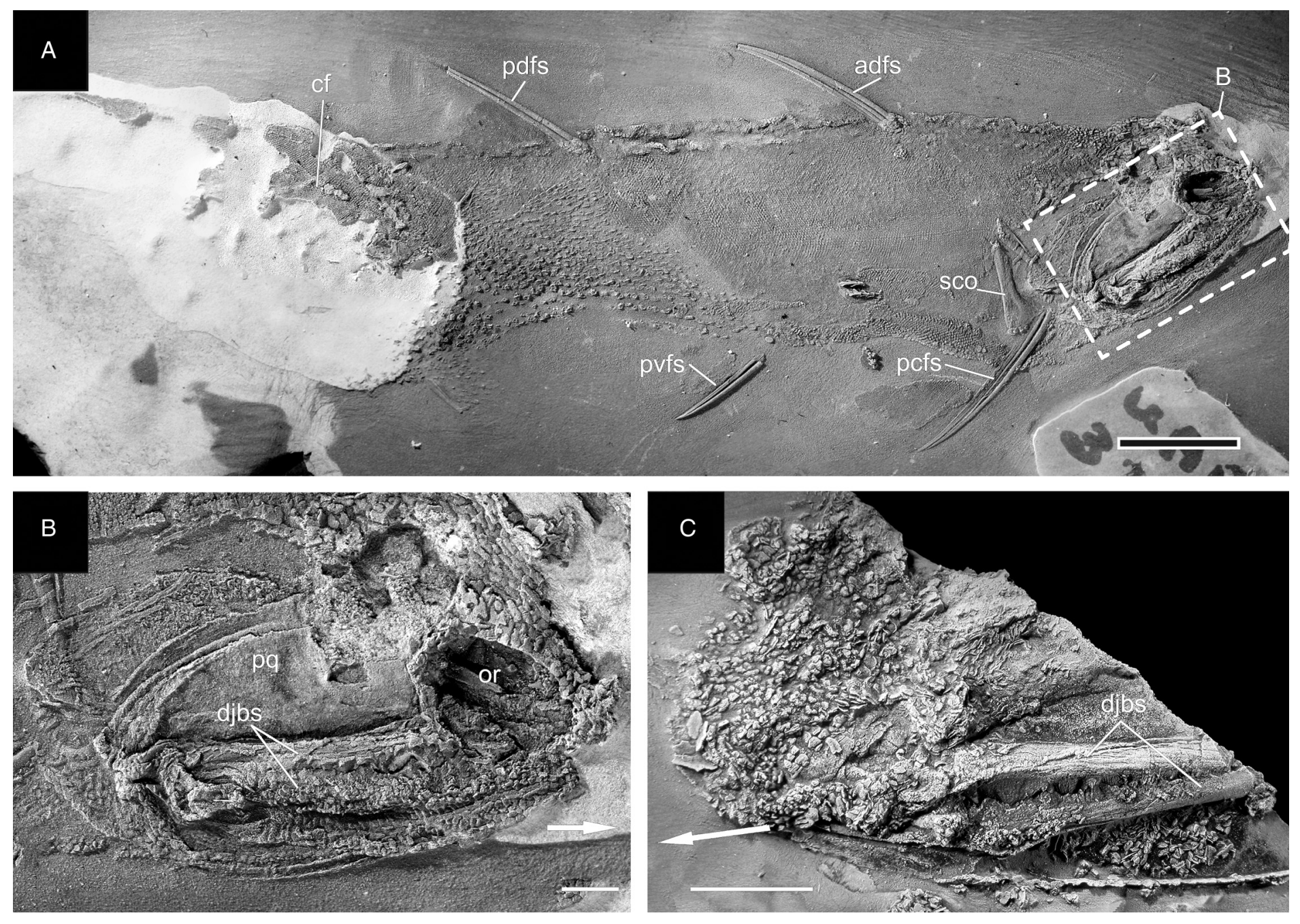

Fig. 1. Articulated specimens of ischnacanthiform acanthodians from the Early Devonian MOTH locality. (A) UALVP 32401, an articulated, nearly complete specimen, preserved in right lateral view; (B) close-up of the area outlined by the dashed rectangle in (A); and (C) UALVP 42055, an articulated specimen of the anterior part of the head of an ischnacanthiform acanthodian, preserved in left lateral view. adfs, anterior dorsal fin spine; cf, caudal fin; djbs, dentigerous jaw bones; or, orbit; pcfs, pectoral fin spine; pdfs, posterior dorsal fin spine; pq, palatoquadrate cartilage; pvfs, pelvic fin spine; sco, scapulocoracoid. Arrows indicate anterior in $(B)$ and $(C)$. Scale bar for $(A)$ and $(C)$ is equal to $5 \mathrm{~mm}$; scale bar for $(B)$ is equal to $1 \mathrm{~mm}$.

taxa (Purnell et al. 2006, 2012; Polačik et al. 2014; Knickle and Rose 2014), such closely related coexisting animals as have been described from the MOTH locality would be expected to have exploited different food sources. Because of the lack of direct fossil evidence such as stomach contents or coprolites, this hypothesis has not previously been tested for the MOTH ischnacanthiforms.

In this study, articulated pairs of upper and lower jaws from two different species of ischnacanthiform from the MOTH locality, Euryacanthus rugosus (Blais et al. 2015) and Tricuspicanthus gannitus (Blais et al. 2015) (Fig. 2), were isolated from the surrounding matrix and scanned using micro-computed tomography $(\mu \mathrm{CT})$ to create three-dimensionally sculpted reconstructions. Once reconstructed, the jaws were manipulated digitally to gain a better understanding of how they could have occluded in life. 

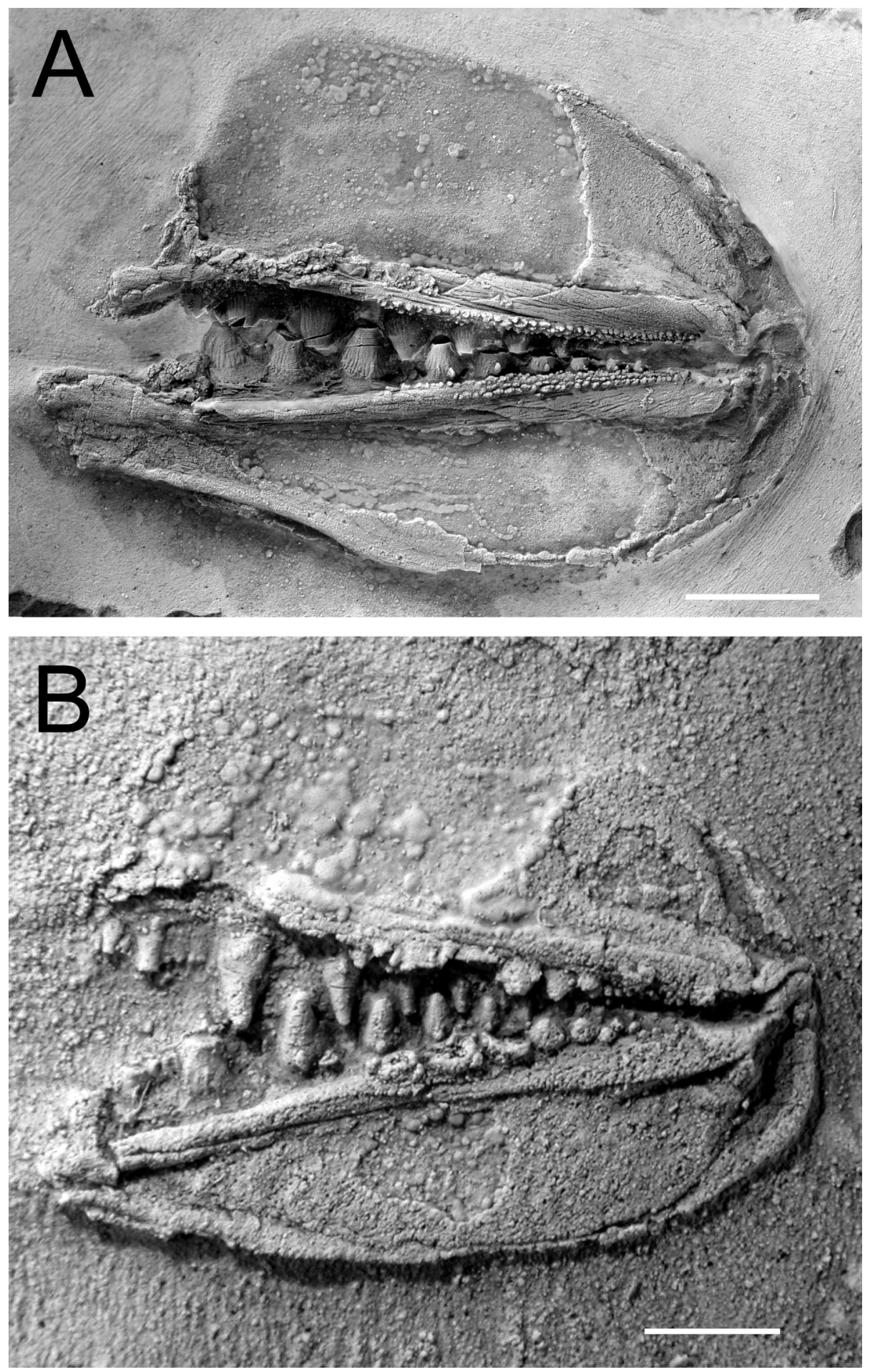

Fig. 2. Articulated upper and lower dentigerous jaw bones and associated cartilages used to create the three-dimensional reconstructions in this study. (A) UALVP 45648, right upper and lower jaws of Euryacanthus rugosus, preserved in lingual view; (B) UALVP 48487, right upper and lower jaws of Tricuspicanthus gannitus, preserved in lingual view. Anterior is to the left. Scale bar for (A) is equal to $5 \mathrm{~mm}$; scale bar for (B) is equal to $1 \mathrm{~mm}$. 


\section{Methods}

\section{Specimen preparation and photography}

Specimens described in this study are housed in the University of Alberta Laboratory for Vertebrate Palaeontology (UALVP) collections. The calcareous matrix of argillaceous limestone in which fossils from MOTH are preserved was removed from the fossils using a solution of dilute acetic acid and soft brushes; fossils were stabilized using a 5\% solution of Glyptal cement in acetone. The specimens were whitened using ammonium chloride sublimate and photographed using a Zeiss Discovery V8 stereomicroscope and Nikon NIS-Elements F 2.20 imaging software. Because the density of the matrix for MOTH specimens is quite high and interferes with CT scanning, the fossils were then embedded in Buehler EpoThin Low Viscosity Resin and Hardener and prepared from the buried side to remove the remaining matrix, separating the fossil entirely from the matrix to facilitate CT scanning. This was not completed for UALVP 45848 because of its status as the holotype specimen of E. rugosus.

\section{X-ray computed tomography and reconstruction}

Specimens UALVP 45648 and UALVP 48487, representing the ischnacanthiform species E. rugosus and T. gannitus, respectively (Fig. 2), were scanned using a SkyScan $1174 \mu \mathrm{CT}$ scanner at $50 \mathrm{kV}$ and $800 \mathrm{uA}$, with a slice thickness of $9 \mu \mathrm{m}$. Slice data were analysed using OsiriX, Mimics, and Avizo 6.3. A stereolithography (.STL) surface mesh of the three-dimensional geometry was created in Mimics from the stacked DICOM (Digital Imaging and Communications in Medicine format) images acquired by the CT scanner. Each .STL file was then imported into Geomagic Studio 6 software. Using the "Sculpt" tool, Geomagic was used to reconstruct broken or missing teeth, using intact specimens of the same species for reference. In particular, UALVP 45050 (fig. 3D in Blais et al. 2015) was used as a reference to reconstruct the broken teeth of UALVP 45648. To reconstruct the broken teeth and missing jaw cartilage of UALVP 48487, UALVP 45078, and UALVP 41920 were used as references (fig. 5 in Blais et al. 2015). The blank labial side of UALVP 45648 was also filled in as flat, as it was reconstructed on the lingual side only and not prepared out of its matrix because of its status as the holotype of the species.

Three-dimensional hollow surface meshes were created for the flattened specimens and manipulated to determine their occlusion. The surface meshes were then sculpted using Geomagic until the curvature of the cartilages in the ischnacanthiform jaw reconstructions (Fig. 3) more closely resembled the curvature of the jaws in related Devonian fossil specimens that were preserved in three dimensions or dorsoventrally exposed, including Ptomacanthus anglicus (Miles 1973), redescribed by Brazeau (2009); Doliodus problematicus (Woodward 1892), based on CT data presented by Maisey et al. (2009, 2014); and Gogoselachus lynbeazleyae (Long et al. 2015a). Although the more laterally flattened MOTH ischnacanthiform jaws may have been less curved than the jaws of these specimens in life, the purpose of curving the jaw reconstructions was to determine whether and how it affected the occlusion of the jaws, not to attempt to recreate an entirely accurate life position. The curved reconstructions were then re-examined to determine whether the interpretation of their occlusal style was significantly affected by their taphonomic deformation. CT scans are reposited at the University of Alberta and are also available with the original .STL files on figshare.com (Blais 2017a, 2017b).

\section{Results}

The three-dimensional surface meshes created from the $\mu \mathrm{CT}$ slice data for the flattened specimens revealed different occlusal styles for the two different species. Neither species exhibited a simple upand-down cog-like style of occlusion in which each cusp proceeded unobstructed to contact the opposing inter-tooth pit. The occlusion of the teeth was restricted by the anterior and posterior lateral flanges associated with each lateral tooth cusp in E. rugosus and by the flanges and posterior teeth in T. gannitus. In the flattened reconstructions created for both species (Fig. 4), the teeth curve slightly medially and 

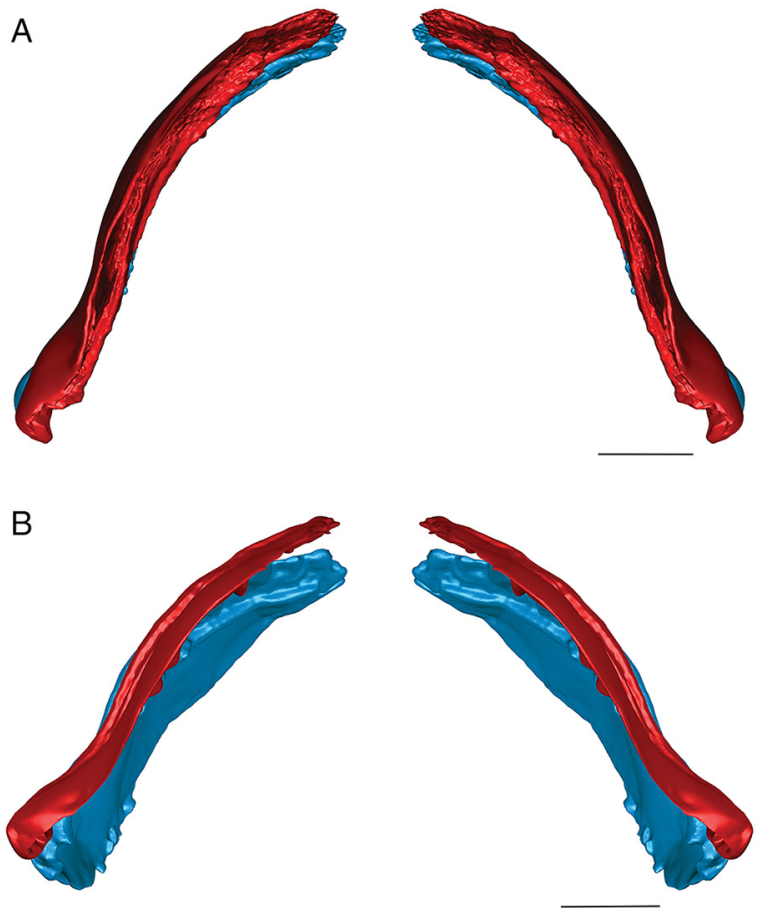

Fig. 3. Three-dimensionally reconstructed ischnacanthiform jaws, sculpted to approximate a similar curvature to that of related fossil taxa preserved dorsoventrally or in three dimensions. (A) Reconstructed jaws of Euryacanthus rugosus, in dorsal view; (B) reconstructed jaws of Tricuspicanthus gannitus, in dorsal view. The palatoquadrate and upper dentigerous jaw bones are rendered in red, whereas the Meckel's cartilage and lower dentigerous jaw bones are rendered in blue. The scale bar for (A) is approximately $5 \mathrm{~mm}$, and the scale bar for (B) is approximately $1 \mathrm{~mm}$. These scale bars are only approximate, based on references from flattened specimens.

interlock, with each tooth cusp being stopped short of and slightly medial to the opposing inter-tooth pit of the opposing jaw as its anterior and posterior labial flanges contact the flanges associated with the opposing teeth on the opposite ramus of the jaw. The main points of contact are between the anterior and posterior surfaces of each tooth cusp, not between the tip of the tooth cusp and the opposing jaw bone. Regardless of the relative positions of each jaw or the distance between the articular cotylus and condyle of the associated jaw cartilages, the teeth fit together in this interlocking pattern.

When the surface mesh reconstructions were subsequently deformed to reflect the curvature of the jaw elements in related Devonian species (Figs. 3, 5, 6), the teeth fit more closely together than in the flat reconstructions. Re-orienting the jaw cartilages "corrected" the medial curve of the teeth, and they occluded more vertically, but the anterior and posterior labial flanges of opposing teeth continued to come into contact with each other before each tooth cusp contacted the inter-tooth pit on the opposing jaw. The teeth still interlock tightly together with the tooth cusps remaining slightly medial to the lateral flanges of the opposing teeth. The main points of contact remain the anterior and posterior surfaces of each tooth cusp. The tooth cusps in both species are unable to contact the inter-tooth pits on the opposing jaws, regardless of the orientation of the jaws.

\section{Euryacanthus rugosus}

The anterior and posterior labial flanges are well developed in E. rugosus, and the teeth occlude tightly together in this species (Figs. 4,5). The large lateral teeth curve slightly medially, even in the curved reconstructions. When the anterior and posterior labial flanges of opposing teeth are in contact with each other, each tooth cusp is slightly "above" (either dorsal or ventral to) and medial to the opposing inter-tooth pit. When the teeth are in contact with each other in the central and anterior parts of the jaw as in the articulated specimens, there is very little open space left between each pair of opposing teeth. The smaller teeth at the anterior and posterior ends of the jaw bones do not contact each other. The anterior and posterior labial flanges form an almost continuous surface when the jaws are tightly closed, coming together like scissor blades. The jaw bones themselves are curved dorsoventrally, so that at the anterior end of the jaws the distance between the upper and lower jaw bone is greatest. Based on 
A

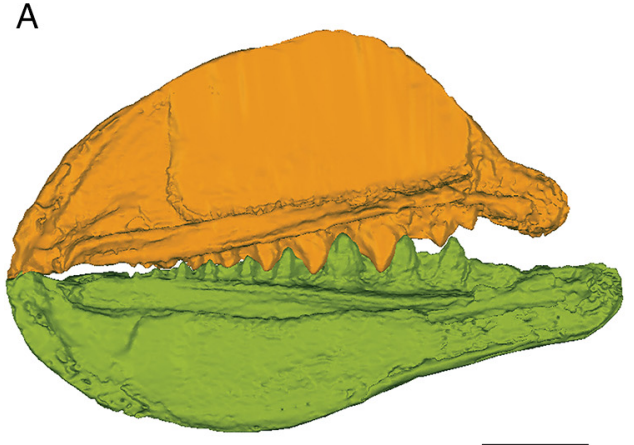

C

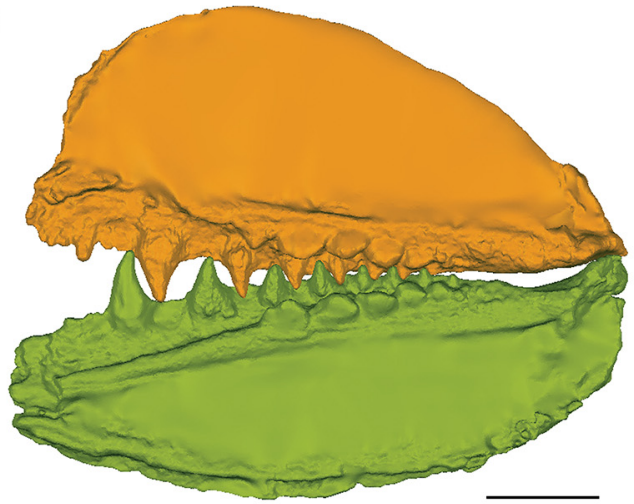

B

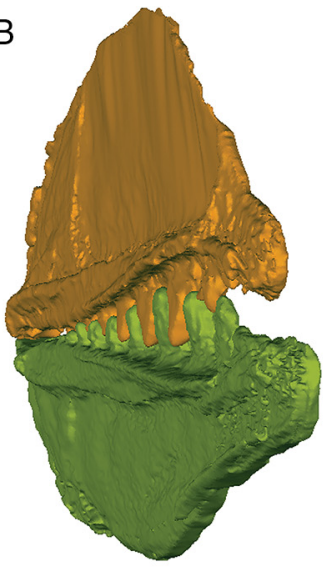

D

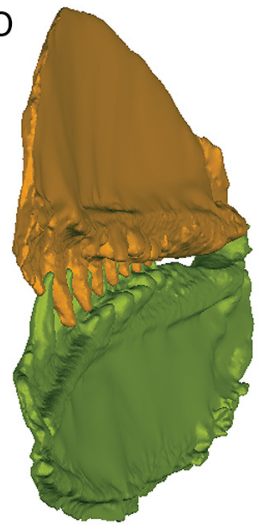

E

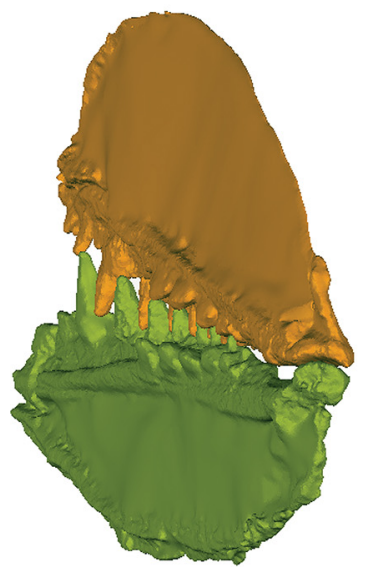

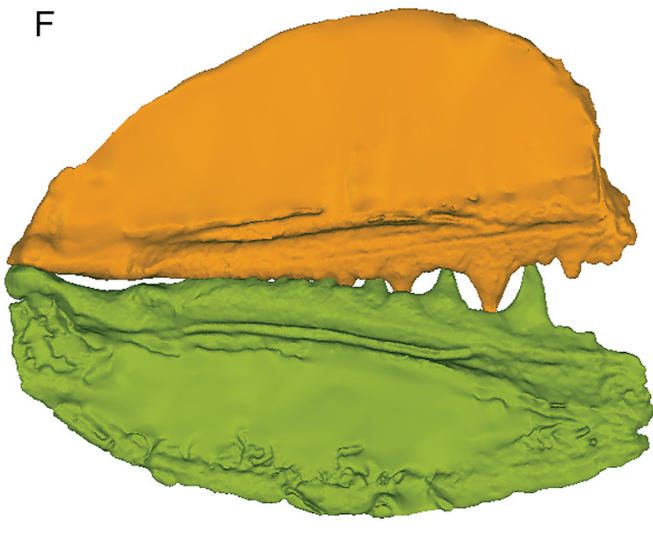

Fig. 4. Three-dimensional reconstructions of flattened specimens of ischnacanthiform jaws, as preserved at the MOTH locality. (A-B) Reconstruction based on UALVP 45648, the holotype of Euryacanthus rugosus; (C-F) reconstruction based on UALVP 48487, Tricuspicanthus gannitus. (A) Reconstruction of the jaw of E. rugosus based on UALVP 45648, lingual view, anterior is to the right; (B) reconstruction of E. rugosus in anterior view; (C) reconstruction of the jaw of T. gannitus based on UALVP 48487, lingual view, anterior is to the left; (D) reconstruction of T. gannitus in anterior view; (E) reconstruction of T. gannitus in posterior view; and (F) reconstruction of T. gannitus in lateral view, anterior is to the right. Upper dentigerous jaw bones and palatoquadrate cartilages are rendered in orange; lower dentigerous jaw bones and Meckel's cartilages are rendered in green. The scale bar for (A) is $5 \mathrm{~mm}$ and the scale bar for $(\mathrm{C})$ is $1 \mathrm{~mm}$. The other figure parts have been rotated, but not resized from the scale in (A) or (C) (e.g., (B) is the same size as (A), but foreshortened by rotating). 


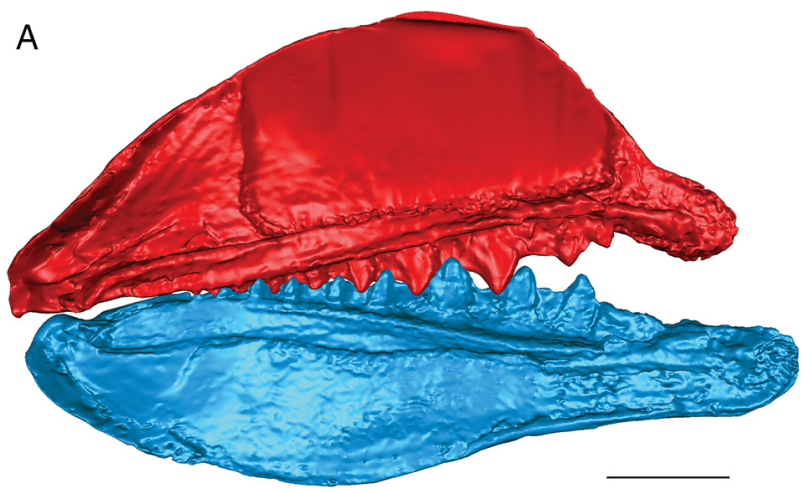

B

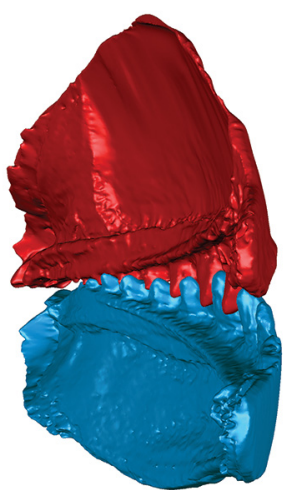

Fig. 5. Three-dimensional reconstruction of the jaws of Euryacanthus rugosus. (A) Reconstructed jaws in lingual view; anterior is to the right; (B) reconstructed jaws in anterior view; lingual is to the left. The upper dentigerous jaw bone and palatoquadrate cartilage are rendered in red. The lower dentigerous jaw bone and Meckel's cartilage are rendered in blue. Scale bar for (A) is $5 \mathrm{~mm}$. (B) is the same size as (A); it has been rotated but not resized. Scale bar is only approximate, based on references from flattened specimens.

articulated ischnacanthiform specimens, this space was probably occupied by large tooth whorls anterior to both the palatoquadrates and Meckel's cartilages. The tooth whorls are almost never preserved in situ, so it is difficult to determine how they may have affected the closure of the jaws.

The lateral teeth are broad, with longer posterior flanges than anterior flanges, and slightly recurved. When the lower jaw is moved relative to the upper jaw to close the jaws, the teeth occlude in a shearing motion. Each upper tooth cusp contacts and shears down the posterior surface of the opposing lower tooth until the posterior flanges contact each other.

\section{Tricuspicanthus gannitus}

The lateral teeth of T. gannitus are less broad than the teeth of E. rugosus, with smaller anterior and posterior labial flanges. The teeth are also longer relative to the overall size of the jaws and more widely spaced than those of E. rugosus. Because of this, the anteriormost teeth do not occlude as closely and there is space left between the opposing anteriormost teeth when the jaws are closed (Figs. 4, 6). The teeth near the center of the jaws occlude tightly, but the posteriormost teeth do not contact the posteriormost teeth on the opposing jaw. The anteriormost and the largest tooth cusps are prevented from contacting the inter-tooth pits on the opposing jaw bone by their associated anterior and posterior labial flanges, which come into contact with the base of the opposing tooth. If the jaw joint is disarticulated (Fig. 6), the space between the anteriormost teeth is reduced but the teeth still do not contact the opposing inter-tooth pits. 

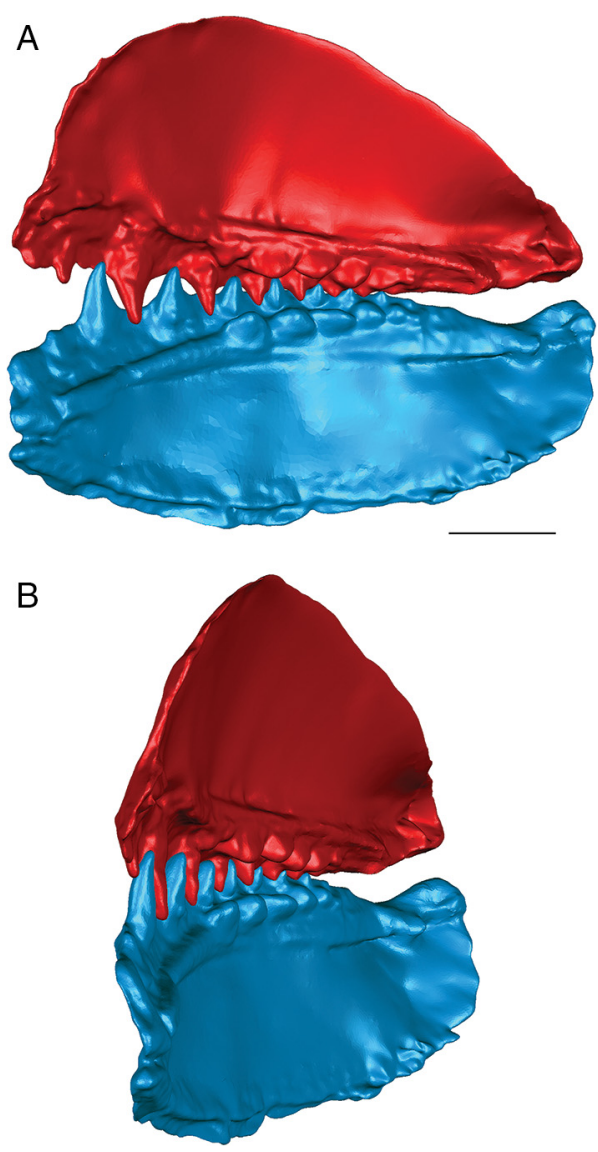

Fig. 6. Sculpted three-dimensional reconstruction of the jaws of Tricuspicanthus gannitus. (A) Reconstructed jaws in lingual view, anterior is to the left; (B) reconstructed jaws in anterior view, lingual is to the right. The upper dentigerous jaw bone and palatoquadrate cartilage are rendered in red. The lower dentigerous jaw bone and Meckel's cartilage are rendered in blue. Scale bar for (A) is $1 \mathrm{~mm}$. (B) is the same size as (A); it has been rotated but not resized. Scale bar is only approximate, based on references from flattened specimens.

The main points of contact of the anteriormost teeth appear to be the lower half of each of the tooth cusps with the anterior and posterior labial flanges of the opposing teeth. The teeth of T. gannitus also appear to occlude via a more vertical motion than the teeth of E. rugosus, but there is still an element of shear in the anteriormost teeth. There is also less distance between the anterior ends of the upper and lower jaws than in E. rugosus, which is likely related to the smaller anterior tooth whorls in this species.

Interestingly, the robust medial teeth of T. gannitus never come into contact with the medial teeth of the opposing jaw, regardless of how the jaws are manipulated. If the lateral teeth occlude in the interlocking manner indicated by the articulated specimens, the medial teeth cannot occlude. Instead, they project either dorsally or ventrally, and slightly medially, into the mouth cavity (Fig. 6).

\section{Discussion}

\section{Trophic niche differentiation}

The three-dimensional reconstructions created for the two species in this study reveal two different and distinct styles of jaw and tooth occlusion. As these species were coeval, the hypothesis that 
ischnacanthiforms can be grouped chronologically based on their jaw occlusion types (Burrow 2004) must, therefore, be rejected. Although the occlusion in T. gannitus is closer to the cog-like vertical tooth closure suggested by Burrow (2004) than is the occlusion in E. rugosus, neither species exactly fits the model proposed for Silurian-Middle Devonian ischnacanthiforms. The teeth of both species occlude in an interlocking fashion similar to that proposed by Ørvig (1973), with a precision unusual for fishes. Because these animals retained their teeth throughout their lives without replacing them, very precisely aligning teeth may have been advantageous. Conversely, if a single tooth was out of alignment with the rest of the teeth in the jaw, the animal's ability to bite effectively would likely have been greatly impacted. In this sense, tooth occlusion in ischnacanthiform acanthodians may be more more comparable to that in most mammals and some other tooth-retaining tetrapods than that in polyphyodont taxa like chondrichthyans and most bony fishes.

Similar to the condition in mammals, it is possible that the differences in the tooth morphology and occlusion between the two species of ischnacanthiforms reflect differences in biting and feeding strategies, which were evidently more varied than expected in at least some Early Devonian ischnacanthiforms. The employment of different biting or chewing strategies by coeval ischnacanthiforms at the MOTH locality provides support for the hypothesis that these two species could have coexisted by partitioning trophic niches and specializing in prey sources. This also supports the hypothesis proposed by Choo et al. (2014) that early gnathostomes had likely undergone significant trophic niche differentiation by the Devonian.

In addition to the indication that the two species of ischnacanthiforms could have specialized in different food sources, the three-dimensional reconstructions also provide some insight into the possible ecological role of each species. The shearing, interlocking occlusion, fang-like curved tooth cusps, and sharp, smooth anterior and posterior labial tooth flanges present in E. rugosus (Fig. 5) suggest that it could have been an effective predator of large prey (relative to its body size), including soft-bodied animals. Tightly interlocking teeth have been suggested as an indicator of macrophagy in crocodylians (Young et al. 2012), and the anterior and posterior flanges would have formed an almost continuous slicing or cutting surface. The teeth of E. rugosus also have longitudinal ridges (Blais et al. 2015), which, in other taxa, have been suggested to indicate the presence of plicidentine (Meunier et al. 2014). Plicidentine is currently unknown in ischnacanthiforms, and a histological analysis of the teeth would be required to determine whether these ridges are the result of infolding of the dentine in Euryacanthus. Plicidentine has been hypothesized to strengthen the attachment of the teeth to the tooth-bearing element of the jaw, particularly in active predators (Scanlon and Lee 2002; Modesto and Reisz 2008; Maxwell et al. 2011a, 2011b; Meunier et al. 2014). Euryacanthus rugosus was also one of the largest ischnacanthiform acanthodians from the Early Devonian MOTH locality, although compared with ischnacanthiforms from other localities and ages, it was a small fish. Taken together, the relative size, jaw occlusion, and tooth morphology suggest an actively predatory ecological role for E. rugosus, which would be further supported if plicidentine was determined to be present.

Because E. rugosus has a single row of teeth on each jaw bone, the tooth occlusion in this species is relatively simple compared with that of $T$. gannitus. Tricuspicanthus gannitus has multiple rows of teeth on each jaw bone and is monognathically heterodont, with striking differences in tooth morphology and occlusion between its lateral and medial dentition (Figs. 4, 6). The lateral teeth of T. gannitus are long, widely spaced, and caniniform, typical of the "piercing graspers" of Bellwood et al. (2014). These teeth could have been well suited to puncturing soft prey. The medial teeth, however, are blunt, robust, and low crowned, typical of animals interpreted to be durophagous (Pregill 1984; Motani 2005; Choo et al. 2014; Crofts and Summers 2014). Two very different forms of teeth on the same tooth-bearing element in the jaw could be indicative of several possible feeding 
strategies. Perhaps T. gannitus exploited a wide range of food sources, using its lateral dentition to puncture softer prey and using its robust medial teeth to crush hard-shelled animals such as bivalves or arthropods, which were certainly present at the MOTH locality during the Early Devonian. Alternatively, it may have specialized in hard-shelled prey, grasping with its lateral teeth and crushing with its medial teeth. This type of strategy has been proposed for Megamastax amblyodus (Choo et al. 2014) and could have also been employed by T. gannitus.

It is interesting to note, however, that the medial teeth of the upper and lower jaws in this species cannot come into contact with each other, indicating that $T$. gannitus would have only been able to effectively crush shelled prey that was larger than the gap between the upper and lower medial tooth rows. This suggests that not only might $T$. gannitus have specialized in hard-shelled prey, but specifically large hard-shelled prey ("large" being relative to the size of $T$. gannitus, one of the smallest ischnacanthiforms from MOTH). Of the possible candidates for such prey known from the MOTH locality, eurypterids and molluscs seem the most likely. It is also possible that T. gannitus could have ingested small, subadult heterostracans or osteostracans, fossils of which have been recovered from the MOTH locality (Greeniaus and Wilson 2003; Hawthorn et al. 2008). Finally, it is possible that T. gannitus specialized in hard-shelled prey until it reached a certain size; perhaps while its lateral dentition remained relatively small, its medial dentition would have been more effective on smaller prey such as ostracods, which were also relatively abundant at the MOTH locality (Zorn et al. 2005). Judging from the relative abundance of specimens of T. gannitus compared with the other ischnacanthiform species from MOTH (Blais et al. 2015), whatever feeding strategy it employed seems to have been a successful one.

Tricuspicanthus gannitus has very tightly packed, needle-like lip scales that cover the posterior half of the jaws in articulated specimens (Blais et al. 2011). These lip scales appear to form a continuous cover, intermeshing with no obvious dividing line between the posterior part of the upper and lower halves of the jaws (Fig. 7). This indicates that the posterior region of the mouth in these animals was enveloped by a layer of skin, which would have supported the scales. Effectively, T. gannitus may have had cheeks. They also possessed tiny, sharp scales lining the inside of the oral cavity (Blais et al. 2015). If these ischnacanthiforms were eating soft-bodied prey or separating the soft parts from hard-shelled prey, perhaps the combination of a membranous cheek and sandpaper-like roughened internal oral surface combined to prevent the prey tissue from sliding out of the mouth during processing and position it more precisely for chewing. Taken together, these features suggest that postcapture processing of prey may have been present in T. gannitus.

\section{Tooth wear in ischnacanthiforms}

According to the hypothesis posited by Ørvig (1973), the posterior tooth cusps in ischnacanthiform acanthodians were worn down to "stumps" by regularly coming into contact with the inter-tooth pit on the occlusal surface of the opposing jaw bone. If the tips of the posterior tooth cusps were being ground away by such contact, one would expect the surficial orthodentine layer of the apices of the posteriormost tooth cusps to be truncated and worn away, exposing the core of the tooth. Thin sections of ischnacanthiform dentigerous jaw bones from the MOTH locality have revealed that the surficial orthodentine layer covering the posteriormost teeth is continuous with that covering the anteriormost teeth (MacKenzie 2008). Although they are lower and more rounded than the anteriormost teeth, the posteriormost tooth cusps do not appear to be significantly worn relative to the anteriormost tooth cusps in MOTH ischnacanthiforms, and the cores of the posteriormost teeth are not exposed.

This lack of significant wear on the posteriormost tooth cusps relative to the anteriormost tooth cusps can be explained using the model of jaw and tooth occlusion proposed in this study. The main points of contact between teeth according to the three-dimensional reconstructions of $T$. gannitus and E. rugosus jaws were not the apices of the tooth cusps, but the anterior and posterior medial 

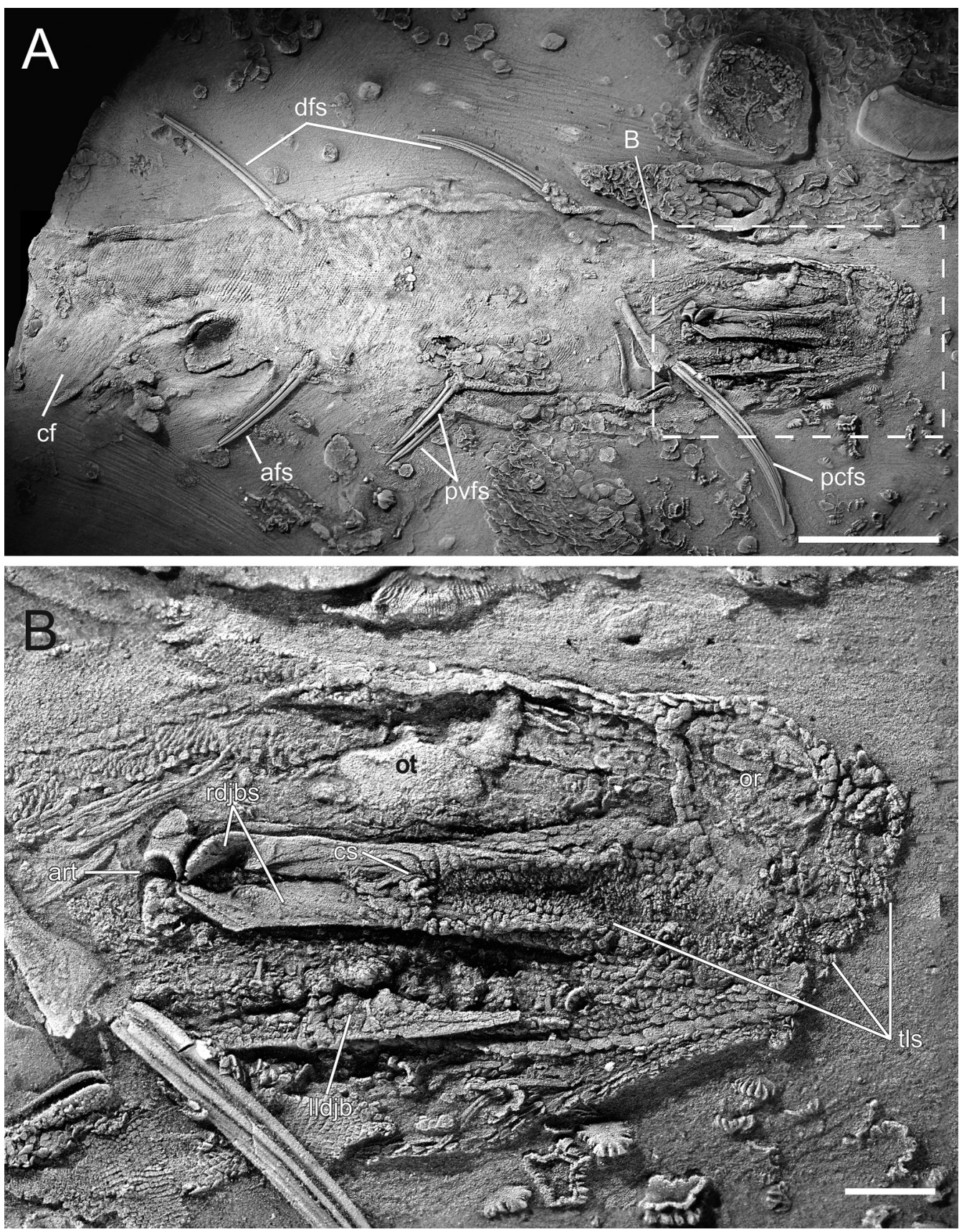

Fig. 7. Articulated nearly complete specimen of Tricuspicanthus gannitus, UALVP 32405. (A) Complete specimen preserved in right lateral view, anterior is to the right; (B) close-up of area outlined by the dashed rectangle in (A). afs, anal fin spine; art, articulation of the palatoquadrate and Meckel's cartilages; cf, caudal fin; cs, cheek scales; dfs, dorsal fin spine; lldjb, lower left dentigerous jaw bone; or, orbit; ot, otic material; pcfs, pectoral fin spine; pvfs, pelvic fin spine; rdjbs, right dentigerous jaw bones; tls, tooth-like scales. Scale bar for (A) is equal to $5 \mathrm{~mm}$; scale bar for (B) is equal to $1 \mathrm{~mm}$. 
surfaces of the tooth cusps. These surfaces are smooth in most ischnacanthiforms from the MOTH locality; in species with medial denticles or cuspules associated with each tooth cusp, these are medial to the center of the tooth cusp, with smooth unornamented regions on the anterior and posterior surfaces.

A newly discovered Silurian ischnacanthiform specimen from the MOTH locality (Blais, in review) exhibits evidence of tooth-on-tooth wear in these animals. Although not a member of one of the species for which the three-dimensional reconstructions were created, it was likely closely related, based on similar tooth and jaw morphology. It is likely that its jaws could have occluded in an interlocking, shearing manner similar to that of E. rugosus. It has prominent wear facets on the anterior and posterior lingual surfaces of its lateral tooth cusps that do not extend to the apex of the tooth cusp. This wear pattern supports the manner of occlusion proposed here, in which the teeth interlock and the tooth cusps do not come into contact with the inter-tooth pits of the opposing jaw bone. This evidence of interlocking tooth-tooth contact also supports the hypothesis that these fishes were likely active predators consuming relatively large prey, and that acanthodians were specialized, predatory feeders by the Late Silurian.

\section{Conclusions}

Micro-CT scan data were used to create three-dimensional reconstructions of articulated upper and lower ischnacanthiform jaws representing two coeval Early Devonian species, E. rugosus and T. gannitus. Reconstruction of the jaws in a more true-to-life position allowed their occlusion to be more accurately assessed than using taphonomically flattened specimens alone. This method may be useful for interpreting the ecology of similar groups of closely related taxa if more direct means of inferring trophic niche, such as stomach contents or coprolites, are unavailable.

This study provides valuable insight into the feeding mechanics and ecology of ischnacanthiform acanthodians from the MOTH locality. Euryacanthus rugosus and T. gannitus exhibit differing styles of jaw and tooth occlusion, suggesting that these species captured and processed prey differently. This method thus provides support for a hypothesis of trophic niche differentiation and insight into specialized feeding strategies among these ancient vertebrate predators from the Early Devonian MOTH locality.

\section{Acknowledgements}

I thank AL Lindoe for his skill in preparing the fossils featured in this study. Many thanks are also owed to AM Murray for the use of her microscope array and imaging software, and to VM Arbour and ME Burns for their advice and instruction with $\mu \mathrm{CT}$ and digital reconstruction of fossil specimens. Finally, thanks to AM Murray, MW Caldwell, R Cloutier, DO Lamoureux, MVH Wilson, DC Evans, and two anonymous reviewers for their constructive review of an earlier version of this manuscript, and to T Samman for her assistance. This research was supported by a Natural Sciences and Engineering Research Council of Canada (NSERC) Discovery Grant A9180 to MVH Wilson, and by an NSERC Alexander Graham Bell Canada Graduate Doctoral Scholarship (CGS-D) and University of Alberta scholarships to the author.

\section{Author contributions}

Conceived and designed the study: SAB. Performed the experiments/collected the data: SAB. Analyzed and interpreted the data: SAB. Contributed resources: SAB. Drafted or revised the manuscript: SAB. 


\section{Competing interests}

The author has declared that no competing interests exist.

\section{Data accessibility statement}

All relevant data are within the paper and reposited at the University of Alberta (CT scans). CT scans are also available with the original .STL files on figshare.com (doi.org/10.6084/m9.figshare.4954478.v1 and doi.org/10.6084/m9.figshare.4954436.v1).

\section{References}

Bellwood DR, Hoey AS, Bellwood O, and Goatley CHR. 2014. Evolution of long-toothed fishes and the changing nature of fish-benthos interactions on coral reefs. Nature Communications, 5: 3144. PMID:24423941. doi:10.1038/ncomms4144.

Bernacsek GM, and Dineley DL. 1977. New acanthodians from the Delorme Formation (Lower Devonian) of N.W.T., Canada. Palaeontographica, Abteilung A, 159: 1-25.

Blais S. 2017a. Euryacanthus rugosus jaws: micro-CT slice images and .STL. figshare. doi:10.6084/m9. figshare.4954478.v1.

Blais S. 2017b. Tricuspicanthus gannitus jaws: micro-CT slice images and .STL. figshare. doi:10.6084/ m9.figshare.4954436.v1.

Blais SA, MacKenzie LA, and Wilson MVH. 2011. Tooth-like scales in Early Devonian eugnathostomes and the 'outside-in' hypothesis for the origins of teeth in vertebrates. Journal of Vertebrate Paleontology, 31: 1189-1199. doi:10.1080/02724634.2011.607992.

Blais SA, Hermus CR, and Wilson MVH. 2015. Four new Early Devonian ischnacanthid acanthodians from the Mackenzie Mountains, Northwest Territories, Canada: an early experiment in dental diversity. Journal of Vertebrate Paleontology, 35: e948546. doi:10.1080/02724634.2014.948546.

Brazeau MD. 2009. The braincase and jaws of a Devonian 'acanthodian' and modern gnathostome origins. Nature, 457: 305-308. PMID:19148098. doi:10.1038/nature07436.

Burrow CJ. 2003. Redescription of the gnathostome fish fauna from the mid-Palaeozoic Silverband Formation, the Grampians, Victoria. Alcheringa: An Australasian Journal of Palaeontology, 27: 37-49. doi:10.1080/03115510308619543.

Burrow CJ. 2004. Acanthodian fishes with dentigerous jaw bones: the Ischnacanthiformes and Acanthodopsis. Fossils and Strata, 50: 8-22.

Burrow CJ. 2007. Early Devonian (Emsian) acanthodian faunas of the Western USA. Journal of Paleontology, 81: 824-840. doi:10.1666/pleo06-009.1.

Burrow CJ, and Rudkin D. 2014. Oldest near-complete acanthodian: the first vertebrate from the Silurian Bertie Formation Konservat-Lagerstätte, Ontario. PLoS ONE, 9: e104171. PMID:25093877. doi:10.1371/journal.pone.0104171.

Burrow CJ, den Blaauwen J, Newman M, and Davidson R. 2016. The diplacanthid fishes (Acanthodii, Diplacanthiformes, Diplacanthidae) from the Middle Devonian of Scotland. Palaeontologia Electronica, 19, 19.1.10A :1-83. [online]: Available from palaeo-electronica.org/content/2016/ 1398-scottish-diplacanthid-fishes. 
Choo B, Zhu M, Zhao W, Jia L, and Zhu Y. 2014. The largest Silurian vertebrate and its palaeoecological implications. Scientific Reports, 4: 5242. PMID:24921626. doi:10.1038/srep05242.

Crofts SB, and Summers AP. 2014. How to best smash a snail: the effect of tooth shape on crushing load. Journal of the Royal Society Interface, 11: 20131053. PMID:24430124. doi:10.1098/ rsif.2013.1053.

Darras LPG. 2012. The evolution and macroecological consequences of grazing and shell-crushing in fishes. Ph.D. dissertation, University of Leicester, Leicester, UK. 218 p.

Davis SP, Finarelli JA, and Coates MI. 2012. Acanthodes and shark-like conditions in the last common ancestor of modern gnathostomes. Nature, 486: 247-250. PMID:22699617. doi:10.1038/ nature11080.

Denison RH. 1979. Handbook of paleoichthyology, Part 5: Acanthodii. Gustav Fischer Verlag, Stuttgart, Germany. 222 p.

Gagnier P-Y, Hanke GF, and Wilson MVH. 1999. Tetanopsyrus lindoei gen. et sp. nov., an Early Devonian acanthodian from the Northwest Territories, Canada. Acta Geologica Polonica, 49: 81-96.

Gibson SZ. 2015. Evidence of a specialized feeding niche in a Late Triassic ray-finned fish: evolution of multidenticulate teeth and benthic scraping in †Hemicalypterus. The Science of NatureNaturwissenschaften, 102: 10. PMID:25686871. doi:10.1007/s00114-015-1262-y.

Giles S, Friedman M, and Brazeau MD. 2015. Osteichthyan-like cranial conditions in an Early Devonian stem gnathostome. Nature, 520: 82-85. PMID:25581798. doi:10.1038/nature14065.

Greeniaus JW, and Wilson MVH. 2003. Fossil juvenile Cyathaspididae (Heterostraci) reveal rapid cyclomorial development of the dermal skeleton. Journal of Vertebrate Paleontology, 23: 483-487. doi:10.1671/0272-4634(2003)023[0483:FJCHRR]2.0.CO;2.

Hairapetian V, Valiukevičius J, and Burrow CJ. 2006. Early Frasnian acanthodians from central Iran. Acta Palaeontologica Polonica, 51: 499-520. [online]. Available from app.pan.pl/archive/published/ app51/app51-499.pdf.

Hanke GF. 2002. Paucicanthus vanelsti gen. et sp. nov., an Early Devonian (Lochkovian) acanthodian that lacks paired fin-spines. Canadian Journal of Earth Sciences, 39: 1071-1083. doi:10.1139/e02-023.

Hanke GF, and Wilson MVH. 2004. New teleostome fishes and acanthodian systematic. In Recent advances in the origin and early radiation of vertebrates. Edited by G Arratia, MVH Wilson, and R Cloutier. Verlag Dr. Friedrich Pfeil, Munchen, Germany. pp. 189-216.

Hanke GF, and Wilson MVH. 2006. Anatomy of the Early Devonian acanthodian Brochoadmones milesi based on nearly complete body fossils, with comments on the evolution and development of paired fins. Journal of Vertebrate Paleontology, 26: 526-537. doi:10.1671/0272-4634(2006)26[526: AOTEDA]2.0.CO;2.

Hanke GF, Davis SP, and Wilson MVH. 2001a. New species of the acanthodian genus Tetanopsyrus from northern Canada, and comments on related taxa. Journal of Vertebrate Paleontology, 21: 740-753. doi:10.1671/0272-4634(2001)021[0740:nsotag]2.0.co;2. 
Hanke GF, Wilson MVH, and Lindoe LA. 2001b. New species of Silurian acanthodians from the Mackenzie Mountains, Canada. Canadian Journal of Earth Sciences, 38: 1517-1529. doi:10.1139/ e01-039.

Hawthorn JR, Wilson MVH, and Falkenberg AB. 2008. Development of the dermoskeleton in Superciliaspis gabrielsei (Agnatha: Osteostraci). Journal of Vertebrate Paleontology, 28: 951-960. doi:10.1671/0272-4634-28.4.951.

Karatajute-Talimaa V, and Smith MM. 2002. Early acanthodians from the Lower Silurian of Asia. Earth and Environmental Science Transactions of The Royal Society of Edinburgh, 93: 277-299. doi:10.1017/S0263593300000444.

Knickle DC, and Rose GA. 2014. Dietary niche partitioning in sympatric gadid species in coastal Newfoundland: evidence from stomachs and C-N isotopes. Environmental Biology of Fishes, 97: 343-355. doi:10.1007/s10641-013-0156-0.

Long JA. 1986. New ischnacanthid acanthodians from the Early Devonian of Australia, with comments on acanthodian interrelationships. Zoological Journal of the Linnean Society, 87: 321-339. doi:10.1111/j.1096-3642.1986.tb01339.x.

Long JA, Burrow CJ, Ginter M, Maisey JG, Trinajstic KM, Coates MI, et al. 2015a. First shark from the Late Devonian (Frasnian) Gogo Formation, Western Australia sheds new light on the development of tessellated calcified cartilage. PLoS ONE, 10: e0126066. PMID:26020788. doi:10.1371/journal. pone.0126066.

Long JA, Mark-Kurik E, Johanson Z, Lee MSY, Young GC, Zhu M, et al. 2015b. Copulation in antiarch placoderms and the origin of gnathostome internal fertilization. Nature, 517: 196-199. PMID:25327249. doi:10.1038/nature13825.

MacKenzie LA. 2008. Dentitions of the Eugnathostomata from the Lochkovian (Early Devonian) of the Mackenzie Mountains, Northwest Territories, Canada. M.Sc. thesis, Department of Biological Sciences, University of Alberta, Edmonton, Alberta. 221 p.

Maisey JG, Miller RF, and Turner S. 2009. The braincase of the chondrichthyan Doliodus from the Lower Devonian Campbellton Formation of New Brunswick, Canada. Acta Zoologica, 90: 109-122. doi:10.1111/j.1463-6395.2008.00330.x.

Maisey JG, Turner S, Naylor GJP, and Miller RF. 2014. Dental patterning in the earliest sharks: implications for tooth evolution. Journal of Morphology, 275: 586-596. PMID:24347366. doi:10.1002/ jmor.20242.

Maxwell EE, Caldwell MW, and Lamoureux DO. 2011a. The structure and phylogenetic distribution of amniote plicidentine. Journal of Vertebrate Paleontology, 31: 553-561. doi:10.1080/ 02724634.2011 .557117$.

Maxwell EE, Caldwell MW, Lamoureux DO, and Budney LA. 2011b. Histology of tooth attachment tissues and plicidentine in Varanus (Reptilia: Squamata), and a discussion of the evolution of amniote tooth attachment. Journal of Morphology, 272: 1170-1181. PMID:21618268. doi:10.1002/jmor.10972.

Meunier FJ, De Mayrinck D, and Brito PM. 2014. Presence of plicidentine in the labial teeth of Hoplias aimara (Erythrinidae; Ostariophysi; Teleostei). Acta Zoologica, 180: 174-180. doi:10.1111/ azo.12065. 
Miles RS. 1973. Articulated acanthodian fishes from the Old Red Sandstone of England: with a review of the structure and evolution of the acanthodian shoulder-girdle. Bulletin of the British Museum (Natural History), Geology, 24: 113-213.

Modesto SP, and Reisz RR. 2008. New material of Colobomycter pholeter, a small parareptile from the Lower Permian of Oklahoma. Journal of Vertebrate Paleontology, 28: 677-684. doi:10.1671/ 0272-4634(2008)28[677:NMOCPA]2.0.CO;2.

Motani R. 2005. Detailed tooth morphology in a durophagous ichthyosaur captured by 3D laser scanner. Journal of Vertebrate Paleontology, 25: 462-465. doi:10.1671/0272-4634(2005)025[0462: DTMIAD]2.0.CO;2.

Ørvig T. 1973. Acanthodian dentition and its bearing on the relationships of the group. Palaeontographica, Abteilung A, 143: 119-150.

Polačik M, Harrod C, Blažek R, and Reichard M. 2014. Trophic niche partitioning in communities of African annual fish: evidence from stable isotopes. Hydrobiologia, 721: 99-106. doi:10.1007/ s10750-013-1652-0.

Pregill G. 1984. Durophagous feeding adaptations in an amphisbaenid. Journal of Herpetology, 18: 186-191. doi:10.2307/1563747.

Purnell MA, Hart PJB, Baines DC, and Bell MA. 2006. Quantitative analysis of dental microwear in threespine stickleback: a new approach to analysis of trophic ecology in aquatic vertebrates. Journal of Animal Ecology, 75: 967-977. PMID:17009760. doi:10.1111/j.1365-2656.2006.01116.x.

Purnell MA, Seehausen O, and Galis F. 2012. Quantitative three-dimensional microtextural analyses of tooth wear as a tool for dietary discrimination in fishes. Journal of the Royal Society Interface, 9: 2225-2233. PMID:22491979. doi:10.1098/rsif.2012.0140.

Scanlon JD, and Lee MSY. 2002. Varanoid-like dentition in primitive snakes (Madtsoiidae). Journal of Herpetology, 36: 100-106. doi:10.1670/0022-1511(2002)036[0100:VLDIPS]2.0.CO;2.

Scott BR, and Wilson MVH. 2012. A new species of Waengsjoeaspis (Cephalaspidomorpha, Osteostraci) from the Early Devonian of northwestern Canada, with a redescription of W. nahanniensis and implications for growth, variation, morphology, and phylogeny. Journal of Vertebrate Paleontology, 32: 1235-1253. doi:10.1080/02724634.2012.694514.

Valiukevičius J. 1992. First articulated Poracanthodes from the Lower Devonian of Severnaya Zemlya. In Fossil fishes as living animals. Edited by E Mark-Kurik. Academia 1, Academy of Sciences of Estonia, Tallinn, Estonia. pp. 193-213.

Voichyshyn V, and Szaniawski H. 2012. Acanthodian jaw bones from Lower Devonian marine deposits of Podolia, Ukraine. Acta Palaeontologica Polonica, 57: 879-896. doi:10.4202/app.2011.0079.

Woodward AS. 1892. On the Lower Devonian fish-fauna of Campbellton, New Brunswick. Geological Magazine, 9: 1-6. doi:10.1017/S0016756800188533.

Young MT, Brusatte SL, Beatty BL, De Andrade MB, and Desojo JB. 2012. Tooth-on-tooth interlocking occlusion suggests macrophagy in the Mesozoic marine crocodylomorph Dakosaurus. The Anatomical Record, 295: 1147-1158. PMID:22577071. doi:10.1002/ar.22491. 
Zhu M, Yu X, Ahlberg PE, Choo B, Lu J, Qiao T, et al. 2013. A Silurian placoderm with osteichthyanlike marginal jaw bones. Nature, 502: 188-193. PMID:24067611. doi:10.1038/nature12617.

Zorn ME, Caldwell MW, and Wilson MVH. 2005. Lithological analysis of the Lower Devonian vertebrate-bearing beds at the MOTH locality, N.W.T., Canada: insights to taphonomy and depositional setting. Canadian Journal of Earth Sciences, 42: 763-775. doi:10.1139/e05-015. 